\title{
Campylobacter-associated hospitalisations in an Australian provincial setting
}

\author{
Cameron R. M. Moffatt ${ }^{*}$ (D), Karina J. Kennedy ${ }^{2}$, Linda Selvey ${ }^{3}$ and Martyn D. Kirk ${ }^{1}$
}

\begin{abstract}
Background: Campylobacter spp. infections are a globally important cause of enterocolitis, causing substantial morbidity. Capturing accurate information on hospitalisations is challenging and limited population-level data exist to describe the clinico-epidemiological characteristics of hospitalised cases.

Methods: Hospital administrative and laboratory datasets were linked to identify Campylobacter-associated hospitalisations between 2004 and 2013. Accuracy of morbidity coding was assessed using laboratory diagnosis as a gold standard, with health department surveillance data used to calculate population-based rates. Additional patient-level data were collected via review of medical records. Descriptive statistics were used to assess changes in rates and proportions and to assess relationships between key variables including age, length of stay, comorbidity and complications.

Results: In total 685 Campylobacter-associated hospital admissions were identified, with the sensitivity of morbidity coding 52.8\% (95\% Cl 48.9-56.7\%). The mean annual rate of hospitalisation was 13.6\%. Hospitalisation rates were higher for females across most age-groups, while for both genders marked increases were observed for those aged $\geq 60$ years. Median admission age was 39.5 years, with an average length of stay of 3.5 days. Comorbidities were present in 34.5\% (237/685) of admissions, with these patients more likely to develop electrolyte disturbances, hypotension, renal impairment or acute confusion (all $p<0.001$ ). Bacteraemia and acute kidney injury were observed in $4.1 \%$ (28/ $685)$ and $3.6 \%$ (23/685) of admissions, respectively. Inpatient mortality was low (0.15\%).
\end{abstract}

Conclusion: Under reporting of Campylobacter-associated hospitalisations is substantial but can be improved through data linkage. We observed demographic differences among those hospitalised but further work is needed to determine risk factors and predictors for hospitalisation.

Keywords: Campylobacter, Infectious gastroenteritis, Hospitalisation, Length of stay, Comorbidity, Epidemiology, Clinical coding, Data accuracy

\section{Background}

In high-income settings, Campylobacter spp. are the most frequently reported bacterial enteric pathogen, with increasing disease incidence observed in the United States (US), European Union and Australia [1-3]. Campylobacteriosis typically presents as an acute enterocolitis, characterized by profuse diarrhoea and abdominal pain, along

\footnotetext{
* Correspondence: cameron.moffatt@anu.edu.au

${ }^{1}$ National Centre for Epidemiology and Population Health, Research School of Population Health, Australian National University, Canberra, ACT 2602, Australia

Full list of author information is available at the end of the article
}

with nonspecific symptoms including fever, myalgia and lethargy [4]. While uncommon, complications including bacteraemia and post-infectious sequelae such as reactive arthritis and Guillain-Barré syndrome also occur [5-7].

National (and provincial-level) enteric surveillance systems are frequently passive, capturing only limited data on outcomes such as hospitalisation and death [8]. Consequently, estimating hospitalisation has become an established method for describing foodborne-related disease burden [8-10]. Nevertheless, differences in data sources and the assumptions underpinning these methods make

(c) The Author(s). 2021 Open Access This article is licensed under a Creative Commons Attribution 4.0 International License, which permits use, sharing, adaptation, distribution and reproduction in any medium or format, as long as you give appropriate credit to the original author(s) and the source, provide a link to the Creative Commons licence, and indicate if changes were made. The images or other third party material in this article are included in the article's Creative Commons licence, unless indicated otherwise in a credit line to the material. If material is not included in the article's Creative Commons licence and your intended use is not permitted by statutory regulation or exceeds the permitted use, you will need to obtain permission directly from the copyright holder. To view a copy of this licence, visit http://creativecommons.org/licenses/by/4.0/ The Creative Commons Public Domain Dedication waiver (http://creativecommons.org/publicdomain/zero/1.0/) applies to the data made available in this article, unless otherwise stated in a credit line to the data. 
intercountry comparison of hospitalisation rates challenging [8].

Given increasing disease incidence and concerns regarding accuracy of estimates, it is important to re-examine Campylobacter, with the aim of this study to quantify associated hospitalisations and describe their epidemiological and clinical characteristics, including the spectrum of illness, risk factors and associated outcomes.

\section{Methods \\ Setting}

The Australian Capital Territory (ACT) is a self-governing territory in south-eastern Australia, surrounded by the state of New South Wales (NSW). It contains the national capital Canberra, with an estimated population of 410,000 [11]. Two public hospitals service the ACT. Canberra Hospital, an acute care teaching facility of approximately 600 beds, acts as the tertiary referral centre to both the ACT and surrounding parts of NSW, while Calvary Public Hospital, is a smaller acute care teaching facility of approximately 250 beds. Both hospitals support around 550 , 000 people in the ACT and surrounding NSW. Three private hospitals operate within the ACT but only the two public hospitals have emergency departments (EDs).

\section{Outcome definition and objectives}

A Campylobacter-associated admission was defined as any inpatient episode clinically and temporally linked to a hospital-derived Campylobacter isolate. Our study objectives included examining admission counts and calculating hospitalisation rates, describing the clinical and demographic characteristics of admissions and assessing the impact of admission characteristics, including age, gender and comorbidity, on outcomes including length of stay (LOS) and time to admission.

\section{Data sources and data collection Hospital administrative data}

We obtained public hospital admissions data between 01 January 2004 and 31 December 2013, where the International Classification of Diseases (ICD) morbidity code 'A045 Campylobacter enteritis' was recorded as a primary or secondary diagnosis. Included were unit record (UR) and admission numbers, birth dates, gender, admission and discharge dates, admission sources, admission units and discharge destinations. LOS was calculated by subtracting admission from discharge dates, with reporting in whole days. Same day admissions and discharges received a LOS of 1 day. Private hospital admissions were not sought due to the acute nature of campylobacteriosis and absence of private hospital EDs.

\section{Hospital microbiology data}

Hospital microbiology data for the period 01 January 2004 to 31 December 2013 were used to identify admissions where Campylobacter spp. were isolated from clinical samples but where ICD code 'A045' was not assigned. UR and admission numbers, birth dates, gender, isolation dates, specimen type (e.g. faeces, blood), and hospital, ward and unit identifiers were provided, facilitating linkage with administrative data. All Campylobacter diagnoses were made via culture, with routine speciation not performed before 2013. Details on concurrent isolation or detection of additional enteric pathogens were also provided.

\section{Medical record data}

Medical records were reviewed to confirm admissions and retrieve details unavailable via administrative data sets. This included the presence or absence of signs and symptoms, onset dates (defined as the date of earliest diarrhoea), time to admission (defined as difference in whole days between the onset and admission date), travel history, comorbidities, complications and discharge summaries. Time to admission was calculated for initial acute admissions and not for readmissions or inter-state hospital transfers.

Key signs of infection sought included tachycardia (resting heartrate $\geq 110 \mathrm{bpm}$ ), hypotension (systolic blood pressure $<90 \mathrm{mmHg}$ ), electrolyte imbalance (levels outside of typical reference range for serum sodium of 135 $145 \mathrm{mmol} / \mathrm{L}$ and/or potassium of $3.5-5.2 \mathrm{mmol} / \mathrm{L}$ ) and acute renal impairment (levels above typical reference range for serum creatinine in males of $60-110 \mu \mathrm{mol} / \mathrm{L}$ and females of $45-90 \mu \mathrm{mol} / \mathrm{L}$ and/or urea of 3.0 $8.0 \mu \mathrm{mol} / \mathrm{L})$. Charlson Co-morbidity Index (CCI) scores [12] were calculated as a marker of comorbidity.

\section{ACT surveillance notifications and emergency presentation data}

Campylobacter notification data between 01 January 2004 and 31 December 2013 were obtained from the ACT Government Health Directorate. After identifying ACT resident Campylobacter-associated admissions, we sought to link these back to notification data using birth date, gender, postcode and specimen collection date. This enabled calculation of a hospitalisation rate for ACT campylobacteriosis cases. Hospital-generated microbiology data also enabled matching of non-admitted ED presentations to notification data to calculate an ED presentation rate for ACT residents.

\section{Exclusions}

Admissions were excluded if additional enteric pathogens were detected or isolated from a sample, if diarrhoeal symptoms commenced $\geq 48 \mathrm{~h}$ after admission and 
if Campylobacter spp. were isolated during a planned or elective admission. The exception to this was for planned admissions involving bone marrow or stem cell transplantation. Given the importance of microbial translocation and overgrowth in patients being treated for haematological malignancies [13], we postulated this patient group had underlying Campylobacter spp. carriage at the time of admission.

\section{Analysis}

Hospitalisation and non-admitted ED presentation rates were calculated using ACT resident admission and surveillance data. Sensitivity, specificity, positive and negative predictive values for ICD coding using laboratory diagnosis as the gold standard were calculated. Age and gender specific rates of hospitalisation were calculated for ACT residents. Changes in rates and proportions over time were assessed using linear tests for trend, while two-sample tests of proportions were used to assess equality between groups. Relationships between outcome and independent variables were assessed using Pearson's chi-squared or Fisher's exact tests. Equality of median tests and Spearman's correlations were used to analyse non-normally distributed continuous data including age, LOS, CCI score and time to admission.

\section{Results}

Linking hospital administrative data to laboratory data We identified 685 Campylobacter-associated admissions during the study period (Fig. 1). Hospital administrative data identified 52\% (359/685) of admissions, laboratory data 45\% (310/685) with the remaining 16 admissions identified via medical record review. For admissions identified via administrative data, 84\% (300/359) had Campylobacter enteritis recorded as a primary diagnosis code. For admissions identified via laboratory data, primary diagnosis codes were available for $81 \%$ (250/310), with two-thirds (168/250) assigned a non-specific gastroenteritis code. Sensitivity of morbidity coding using laboratory diagnosis as the standard was $52.8 \%$ (95\% CI 48.9-56.7\%), and specificity was $57.1 \%$ (95\% CI $37.2-$ $75.5 \%)$. The positive and negative predictive values were 96.7\% (95\% CI 94.2-98.3\%) and 4.9\% (95\% CI 2.8-7.8\%).

ACT residents comprised 86\% (593/685) of admissions, with a hospitalisation rate of $13.6 \%$ (593/4361) (Fig. 2). EDs were the admission source for $94 \%$ (555/ 593) of ACT resident admissions, with a further $10 \%$ (436/4361) of ACT Campylobacter notifications linked to at least one non-admitted ED presentation. No trends over time were observed in the proportions of Campylobacter-associated admissions or non-admitted ED presentations. Admissions did not appear to show any obvious seasonal pattern (data not shown).

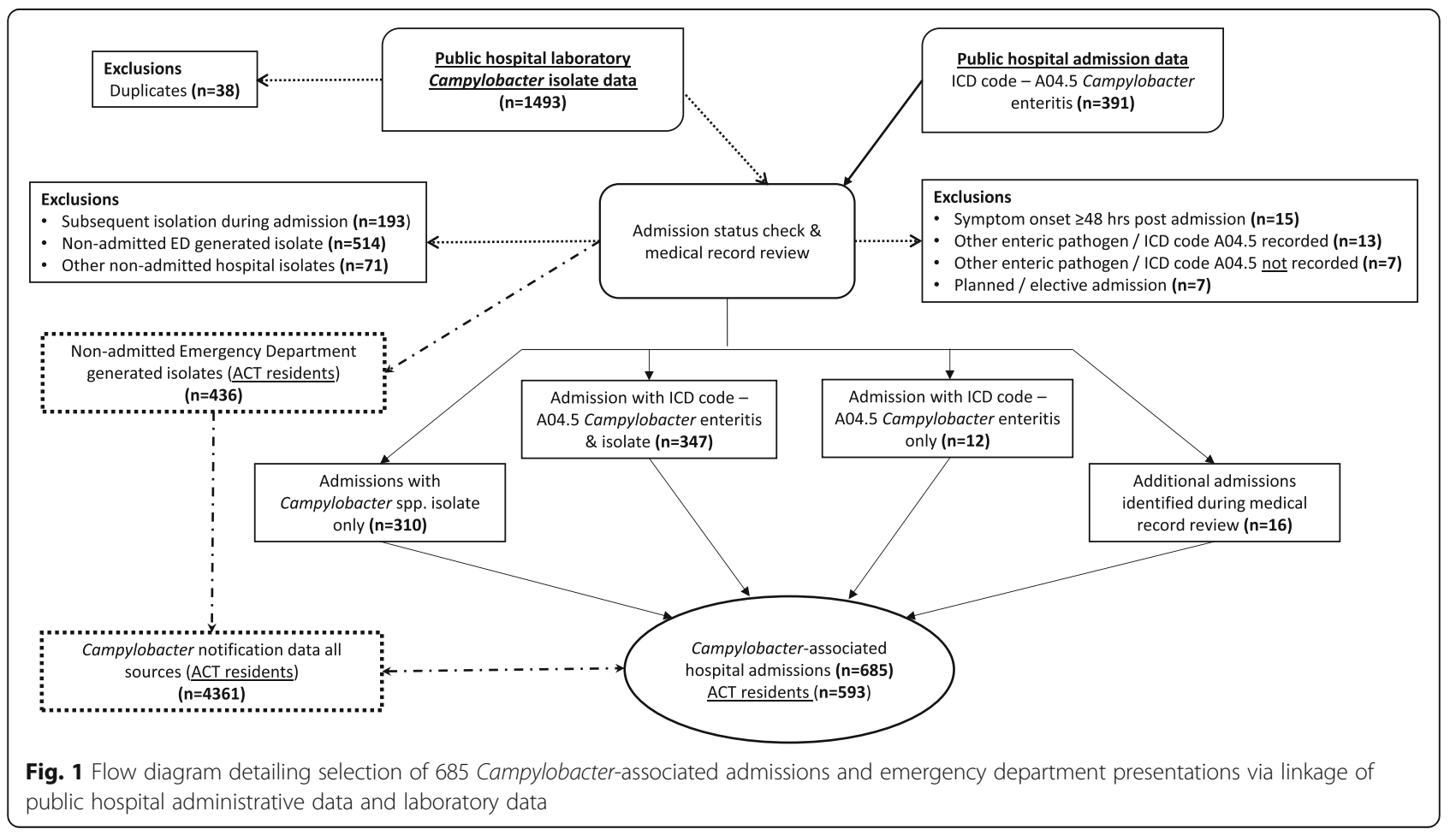




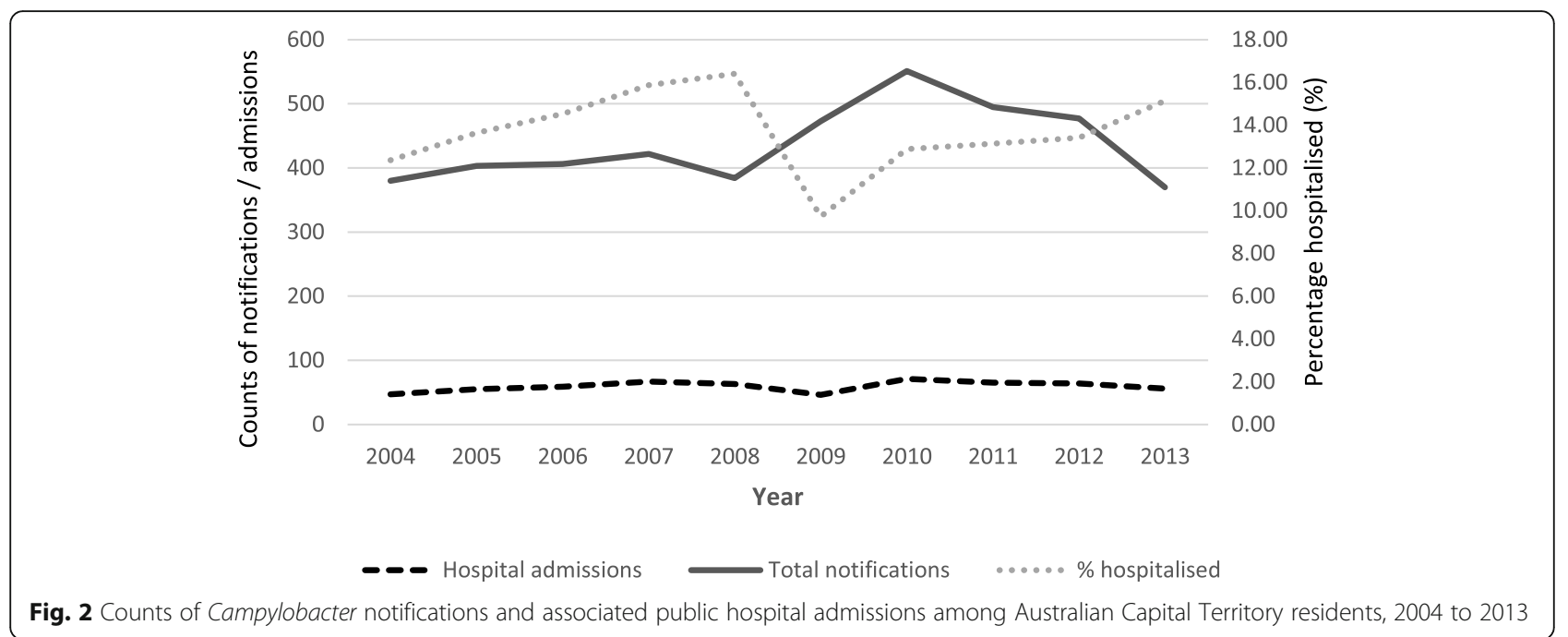

\section{Descriptive characteristics \\ Age and sex characteristics}

Age and sex characteristics are shown in Table 1. Males were older $(M=41.2$ years, range $<1$ to 92.3$)$ than females $(M=38.5$, range $<1.0$ to 92.3$)$ but this difference was not significant. For ACT resident admissions, the median age was 38.4 years (range $<1.0$ to 92.3 years), compared with 31 years (range $<1.0$ year to 99.0 years) among ACT community cases $\left(\mathrm{X}^{2}=17.7, p<0.001\right)$. Non-ACT residents were significantly older $(M=50.8$, range $<1$ year, maximum 90.8 years, $\mathrm{X}^{2}=5.5, p=0.02$ ). Hospitalisation rates increased noticeably among patients aged $\geq 60$ years. The proportion of females admitted across most age-groups was higher than for males, although these differences were small and nonsignificant (Fig. 3).

\section{Prior care, source of admission and admitting unit}

Twenty-seven percent (187/684) of admissions consulted a general practitioner (GP) prior to hospitalisation, while $13.4 \%(92 / 685)$ were hospitalised after an earlier nonadmitted ED presentation. There were 29 admissions (4.2\%) preceded by both GP consultations and nonadmitted ED presentations. EDs were the admission source for $91.8 \%(629 / 685)$ of admissions, with the remainder via community or outpatient admissions, interhospital transfers or care type changes.

Length of stay (LOS) The median LOS for Campylobacter-associated admissions was 2.0 days (range 1.038.0), with no gender or residency differences observed. Exclusion of same day Emergency Medicine unit admissions $(n=180)$, markedly increased the median LOS $(M=3.0$ days, range 1.0-38.0) and average LOS (Table $1)$. A moderately positive correlation between age and
LOS was observed (Spearman's $=0.3557, p=<0.001$ ). Higher median LOS were observed for units including Oncology, Haematology, and Geriatrics, while significant correlations between increasing age and LOS, were observed among General Medicine, Renal Medicine and Gastroenterology admissions (data not shown).

\section{Comorbidities}

Comorbidities were documented in $34.6 \%$ (237/685) of admissions. The most prevalent were diabetes $30.8 \%$ (73/237), malignancies (including solid and disseminated tumours, blood and lymphatic cancers) $27.4 \%$ (65/237), chronic kidney disease $19.0 \%$ (45/237), cerebrovascular disease $17.3 \%(41 / 237)$ and history of myocardial infarction $13.1 \%$ (31/237). The median CCI score was 2 (range 1 to 12$)$. Males comprised 53.6\% (127/237) of admissions with comorbidities but no gender differences in CCI score were observed. Admissions with comorbidities were older, having a median age of 66.7 years (range 3.5 to 92.3 years) versus 28.8 years (range $<1.0$ to 92.3 ) $\left(\mathrm{X}^{2}\right.$ 202.0, $p<0.001)$. A positive correlation between increasing age and CCI scores was observed $\left(\mathrm{r}_{\mathrm{s}}=0.18, n=237\right.$, $p<0.001)$. LOS were longer in admissions with comorbidities, with a median of 4.0 days (range 1.00 to 38.0 days) versus 1.0 day (range 1.0 to $22.0, \mathrm{X}^{2}$ 68.93, $p<$ 0.001 ). A positive correlation between increasing LOS and CCI scores was demonstrated $\left(\mathrm{r}_{\mathrm{s}}=0.25, n=237, p<\right.$ 0.001 ), while a larger proportion of admissions with comorbidities had times to admission greater than the 3 day median $\left(\mathrm{X}^{2} 4.55, p=0.03\right)$.

\section{Time to admission}

The median time between onset and hospitalisation for initial acute admissions $(n=662)$ was 3.0 days (range $<$ 1.0 to 24.0). A higher proportion of females had times to 
Table 1 Demographic and clinical characteristics of 685 Campylobacter-associated admissions in Australian Capital Territory (ACT) public hospitals, 2004-2013

\begin{tabular}{|c|c|}
\hline \multicolumn{2}{|l|}{ Gender } \\
\hline Male (n, \%) & $350(51.0)$ \\
\hline Female & $335(49.0)$ \\
\hline $\mathrm{ACT}$ resident (\%) & $593(86.6)$ \\
\hline Median $(M)$ age in years for all admissions (range) & $\begin{array}{l}39.7(<1.0- \\
92.3)\end{array}$ \\
\hline Indigenous Australian (\%) & $7(1.0)$ \\
\hline \multicolumn{2}{|l|}{ Age-groups $\%$ (hospitalisation rate per 100,000 population ${ }^{\mathrm{a}}$ ) } \\
\hline $0-9$ years $(n=30)$ & $4.38(5.67)$ \\
\hline $10-19$ years $(n=67)$ & $9.78(11.91)$ \\
\hline $20-29$ years $(n=158)$ & $23.07(23.72)$ \\
\hline $30-39$ years $(n=93)$ & $13.58(15.58)$ \\
\hline $40-49$ years $(n=67)$ & $9.78(11.91)$ \\
\hline $50-59$ years $(n=57)$ & $8.32(11.17)$ \\
\hline $60-69$ years $(n=68)$ & $9.93(19.53)$ \\
\hline $70-79$ years $(n=74)$ & $10.80(39.40)$ \\
\hline $80+$ years $(n=71)$ & $10.36(65.35)$ \\
\hline Acute care admission (\%) & $673(98.3)$ \\
\hline Average length of stay (range) & $\begin{array}{l}3.5 \text { days }(1.0- \\
38.0)\end{array}$ \\
\hline Same day acute admissions $(n=268)$ & 1.0 day \\
\hline Non-same day acute admissions $(n=405)$ & $\begin{array}{l}4.9 \text { days }(2.0- \\
38.0)\end{array}$ \\
\hline Other separation types $(n=12)$ & $\begin{array}{l}8.6 \text { days }(1.0- \\
23.0)\end{array}$ \\
\hline Median $(M)$ length of stay (range) & $\begin{array}{l}2.0 \text { days }(1.0- \\
38.0)\end{array}$ \\
\hline Non-same day acute admissions $(n=405)$ & $\begin{array}{l}4.0 \text { days }(2.0- \\
38.0)\end{array}$ \\
\hline $\begin{array}{l}\text { Comorbidity as per Charlson Comorbidity Index (CCI) } \\
\text { (count, (percentage)) }\end{array}$ & $237(34.5)$ \\
\hline \multicolumn{2}{|l|}{ CCl score $(n, \%)$} \\
\hline 1 & $86(36.3)$ \\
\hline 2 & $81(34.2)$ \\
\hline$>2$ (\%, range) & $70(29.5,3-12)$ \\
\hline $\begin{array}{l}\text { Median }(M) \text { time to admission from illness onset for } \\
\text { acute admissions }{ }^{b} \text { (range) }\end{array}$ & $\begin{array}{l}3.0 \text { days }(<1.0- \\
23.0)\end{array}$ \\
\hline \multicolumn{2}{|l|}{ Key signs of infection ${ }^{c}$} \\
\hline Electrolyte disturbance (n, \%) & $410(60.2)$ \\
\hline Tachycardia & $241(35.4)$ \\
\hline Renal impairment & $127(18.7)$ \\
\hline Hypotension & $87(12.8)$ \\
\hline History of recent overseas travel $(n, \%)$ & $11(1.6)$ \\
\hline $\begin{array}{l}\text { Re-admission } \leq 28 \text { days related to campylobacteriosis, } \\
\text { including non-acute status changes }(n, \%)\end{array}$ & $38(5.6)$ \\
\hline Intensive care unit admission (n, \%) & $10(1.5)$ \\
\hline Surgical or invasive diagnostic procedure related to & $45(6.6)$ \\
\hline
\end{tabular}

Table 1 Demographic and clinical characteristics of 685 Campylobacter-associated admissions in Australian Capital Territory (ACT) public hospitals, 2004-2013 (Continued)

campylobacteriosis ( $\mathrm{n}, \%)$

Death during admission or $\leq 28$ days post discharge $(n, 5(0.7)$ $\%)$

Blood sample taken for culture (percentage 333 (7.5) Campylobacter positive)

Antimicrobial therapy during admission ( $n, \%)$

$219(32.0)$

${ }^{\mathrm{a} A C T}$ residents only ${ }^{\mathrm{b}} 636$ observations ${ }^{\mathrm{c}} 681$ observations

admission greater than the median compared to males $\left(\mathrm{X}^{2} 6.03, p=0.01\right)$. A positive correlation between increasing age and time to admission was observed $\left(\mathrm{r}_{\mathrm{s}}=\right.$ $0.15, n=662, p<0.001)$.

\section{Key signs of infection}

These were observed in $74.5 \%(510 / 685)$ of admissions (Table 1), with electrolyte imbalance being the most commonly reported. Renal impairment was associated with any CCI-linked comorbidity $\left(\mathrm{X}^{2}=128.30, p<0.001\right)$ along with male gender $\left(\mathrm{X}^{2}=12.56, p<0.001\right)$. Hypotension $\left(\mathrm{X}^{2}=27.91, p<0.001\right)$ and electrolyte imbalances $\left(\mathrm{X}^{2}=22.24, p<0.001\right)$ were also associated with underlying comorbidities. Correlations between the presence of multiple signs of infection (including electrolyte imbalance, tachycardia, renal impairment and hypotension), and increasing age $\left(\mathrm{r}_{\mathrm{s}}=0.32, n=682, p<\right.$ $0.001)$ and $\operatorname{LOS}\left(\mathrm{r}_{\mathrm{s}}=0.22, n=682, p<0.001\right)$ were observed. Admissions without comorbidities were more likely to have bloody diarrhoea, self-reported fevers, abdominal pain and headaches documented, while key signs of infection and Campylobacter-associated readmissions occurred more frequently in admissions with comorbidities (Table 2).

\section{Complications and other outcomes}

A diversity of complications were documented at discharge, with systemic disease and acute kidney injury the most frequently recorded (Table 3 ). The median age for admissions with systemic disease was 60.8 years (range 12.0 to 90.1 ) compared to 38.6 years (range $<1.0$ to 92.3) among other Campylobacter-associated admissions $\left(\mathrm{X}^{2} 9.60, p=0.002\right)$. The median LOS was 3.5 days (range 1.0 to 28.0 ), being significantly greater than other admissions ( $M 2.0$ days, range 1.0 to $38.0, \mathrm{X}^{2}=7.70, p<$ $0.01)$. An association between comorbidity per se and systemic illness was observed $\left(\mathrm{X}^{2} 8.80, p<0.01\right)$ with individual associations seen for admissions with liver disease $\left(\mathrm{X}^{2}=50.78, p<0.001\right)$ and leukaemia $\left(\mathrm{X}^{2}=5.67 p=\right.$ $0.02)$.

Acute Kidney Injury (AKI) was diagnosed among 3.4\% $(23 / 685)$ of admissions. These were significantly older 


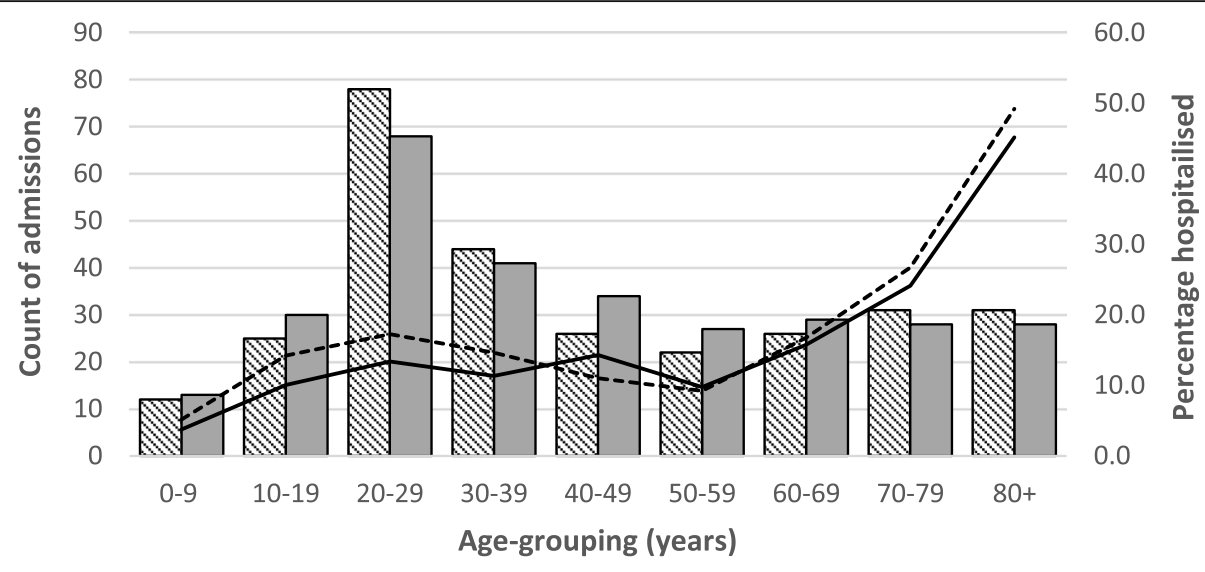

$\$$ Female $\longleftarrow$ Male ------ Female hospt. rate $\longrightarrow$ Male hospt. rate

Fig. 3 Campylobacter-associated public hospital admissions and percentage hospitalised by age-group and gender among Australian Capital Territory residents, 2004-2013

Table 2 Comparison of signs, symptoms, and other outcomes among Campylobacter-associated admissions with and without documented comorbidities (as per Charlson Co-morbidity Index)

\begin{tabular}{|c|c|c|c|c|c|c|c|}
\hline \multirow[b]{2}{*}{ Signs and symptoms associated with enterocolitis } & \multicolumn{4}{|c|}{ Comorbidity present $(n=237)$} & \multirow[b]{2}{*}{ Total } & \multirow[b]{2}{*}{$x^{2}$} & \multirow[b]{2}{*}{$p$-value } \\
\hline & Yes & $\%$ & No & $\%$ & & & \\
\hline Diarrhoea & 231 & 98.7 & 444 & 99.1 & 675 & 0.23 & 0.63 \\
\hline Bloody diarrhoea & 28 & 18.7 & 121 & 35.2 & 149 & 13.51 & $<0.001$ \\
\hline Self-reported fever & 129 & 58.1 & 341 & 78.0 & 470 & 28.57 & $<0.001$ \\
\hline Fever $\left(\geq 38^{\circ} \mathrm{C}\right)$ & 114 & 50.0 & 224 & 51.4 & 338 & 0.11 & 0.74 \\
\hline Abdominal pain & 161 & 81.7 & 403 & 95.7 & 564 & 33.00 & $<0.001$ \\
\hline Nausea & 142 & 79.8 & 311 & 87.6 & 453 & 5.70 & 0.02 \\
\hline Vomiting & 114 & 58.8 & 234 & 56.5 & 348 & 0.27 & 0.60 \\
\hline Myalgia / arthralgia & 35 & 76.1 & 122 & 87.1 & 157 & 3.22 & 0.07 \\
\hline Malaise & 102 & 91.9 & 152 & 96.8 & 254 & 3.18 & 0.07 \\
\hline Headache & 53 & 66.3 & 149 & 89.8 & 202 & 20.31 & $<0.001$ \\
\hline \multicolumn{8}{|l|}{ Key signs and symptoms of infection } \\
\hline Hypotension & 52 & 22.3 & 35 & 7.8 & 87 & 27.94 & $<0.001$ \\
\hline Tachycardia & 89 & 38.2 & 152 & 33.9 & 241 & 1.22 & 0.27 \\
\hline Electrolyte imbalance & 169 & 72.5 & 241 & 53.8 & 410 & 22.46 & $<0.001$ \\
\hline Renal impairment & 98 & 42.1 & 29 & 6.5 & 127 & 127.95 & $<0.001$ \\
\hline Acute confusion & 34 & 14.6 & 4 & 0.9 & 38 & 54.60 & $<0.001$ \\
\hline Bacteraemia & 17 & 7.2 & 11 & 2.5 & 28 & 8.80 & $<0.01$ \\
\hline \multicolumn{8}{|l|}{ Other outcomes } \\
\hline ICU admission & 10 & 4.2 & 0 & - & 10 & & $<0.001^{\mathrm{a}}$ \\
\hline Death within 28 days of discharge & 5 & 2.1 & 0 & - & 5 & & $<0.01^{\mathrm{a}}$ \\
\hline Campylobacter-associated readmission & 22 & 9.3 & 16 & 3.6 & 38 & 9.65 & 0.002 \\
\hline
\end{tabular}

\footnotetext{
a Fisher's exact test
} 
Table 3 Complications recorded at discharge among Campylobacter-associated hospital admissions in the Australian Capital Territory, 2004-2013

\begin{tabular}{|c|c|}
\hline & Frequency (\%) \\
\hline \multicolumn{2}{|l|}{ Extra-intestinal / systemic disease } \\
\hline Bacteraemia (laboratory proven) & $28(4.1 \%)$ \\
\hline Sepsis (discharge diagnosis) & $19(2.8 \%)$ \\
\hline \multicolumn{2}{|l|}{ Intestinal complications } \\
\hline Appendicitis (histologically confirmed) & $8(1.2 \%)$ \\
\hline Mesenteric adenitis & $6(0.9 \%)$ \\
\hline Acute pancreatitis & $4(0.6 \%)$ \\
\hline Acute cholecystitis & $1(0.2 \%)$ \\
\hline \multicolumn{2}{|l|}{ Other significant complication } \\
\hline Acute kidney injury & $23(3.4 \%)$ \\
\hline Acute myocardial infarction & $6(0.9 \%)$ \\
\hline Delirium & $3(0.4 \%)$ \\
\hline Metabolic acidosis & $3(0.4 \%)$ \\
\hline Atrial fibrillation & $2(0.3 \%)$ \\
\hline Rhabdomyolysis & $2(0.3 \%)$ \\
\hline Febrile seizure & $1(0.2 \%)$ \\
\hline Hypovolemic shock & $1(0.2 \%)$ \\
\hline Spontaneous abortion & $1(0.2 \%)$ \\
\hline Perforated diverticulum & $1(0.2 \%)$ \\
\hline Peritonitis & $1(0.2 \%)$ \\
\hline Pulmonary embolism & $1(0.2 \%)$ \\
\hline Thrombocytopaenia & $1(0.2 \%)$ \\
\hline Transient Ischaemic Attack & $1(0.2 \%)$ \\
\hline \multicolumn{2}{|l|}{ Reactive complication } \\
\hline Guillan-Barré Syndrome & $2(0.3 \%)$ \\
\hline Myopericarditis & $2(0.3 \%)$ \\
\hline Reactive arthritis & $1(0.2 \%)$ \\
\hline IgA nephropathy & $1(0.2 \%)$ \\
\hline \multicolumn{2}{|l|}{ Unnecessary surgery } \\
\hline Appendicectomy (normal histology) & $8(1.2 \%)$ \\
\hline
\end{tabular}

( $M 73.9$ years, range 33.2 to 87.5 , median test $\mathrm{X}^{2}=19.92$, $p<0.001$ ), and took longer to present following symptom onset ( $M 5.0$ days, range $<1.0$ to $14, \mathrm{X}^{2}=16.87, p<$ $0.001)$. No differences in gender, LOS or CCI score were observed among acute admissions without AKI. Renal impairment was observed in $18.7 \%(123 / 672)$ of acute admissions. This group was also older $(M 73.8$ years, range 23.7 to $\left.92.3, \mathrm{X}^{2}=101.51, p<0.001\right)$, had longer LOS ( $M$ 4.0 days, range 1.0 to $31.0, \mathrm{X}^{2}=27.91, p<$ 0.001 ), and a greater proportion of admissions with CCI scores $>2\left(M 2\right.$, range 1 to $\left.12, \mathrm{X}^{2}=29.57, \mathrm{p}<0.001\right)$. A significant association with male gender was observed $\left(\mathrm{X}^{2}=12.43, p<0.001\right)$.
Readmissions $\leq 28$ days after discharge occurred among 9.6\% (66/685) of admissions, with 57.6\% (38/66) being Campylobacter-associated. These included 27 admissions for ongoing enterocolitis and 11 for non-acute care. The median age and LOS for acute readmissions were 36.9 years (range 10.1 to 85.6) and 1 day (range 1 to 7 days). No gender-based associations were observed.

Surgical or invasive diagnostic procedures $(n=52)$ were performed during 6.6\% (45/685) of admissions. Colonoscopies accounted for $46 \%$ (24/52), appendectomies $31 \%(16 / 52)$ and gastroscopies $19 \%$ (10/52) of procedures. The median age of those undergoing procedures was 28.8 years (range 12.0 to 81.4 ), significantly lower than for other acute admissions $(M=40.1$ years, range $<1.0$ to $92.3, \mathrm{X}^{2}=8.54, p<0.01$ ), while median LOS was 4 days (range 1 to 22), being compared to 2 days (range 1 to 38 days, $\mathrm{X}^{2}=20.70, p<0.001$ ).

\section{Discussion}

In this study, only one out of every two Campylobacter infections was identified via hospital discharge data. While hospitalisation is considered a marker of severity for foodborne bacterial infections [14], estimating enteric pathogen hospitalisations is challenging given concerns regarding the completeness of surveillance data and the accuracy of pathogen-specific diagnoses and morbidity coding [15]. By identifying all hospital-derived Campylobacter isolates and linking these to inpatient admissions and surveillance data we calculated the sensitivity of morbidity coding associated with Campylobacter infection to be $52 \%$, indicating substantial measurement error. This has been demonstrated in similar settings with US [15] and Swedish [16] studies reporting appropriate use of ICD coding among hospitalised campylobacteriosis cases to be 43 and $51 \%$ respectively.

The $14 \%$ hospitalisation rate we reported is high, reflecting Campylobacter-associated morbidity in Australia [3, 9]. Intercountry comparisons of hospitalisations however reflect differences in incidence and data capture. In New Zealand, $12.6 \%$ of cases were reported as hospitalised (although data was complete for only $62.2 \%$ of cases) [17] while in Germany, where hospitalisation status is routinely collated, the rate was 10\% [18]. Elsewhere hospitalisation rates have ranged from estimates of $5.1 \%$ in Canada [19] to $26.9 \%$ in a Swedish study [16].

Population characteristics of campylobacteriosis in developed settings are typified by increased disease incidence in males and a bimodal age-distribution, with peaks in children aged $<5$ years and adults $<45$ years [20]. We observed higher female admission rates across all age groupings, a finding reported in a number of studies examining hospitalisation for enteric infections $[21,22]$. Reasons for this remain uncertain but inadequate social support for older women has been 
proposed as a contributing factor [21], while our study suggests females may delay seeking care. The increase in admissions aged 20-29 years reflects higher case numbers, with Campylobacter-associated hospitalisation rates increasing most dramatically after 60 years. These observations are consistent with reported changes in the population structure for campylobacteriosis in Australia and similar settings [3, 23], highlighting the potential hospitalisation costs for the elderly and necessitating a need for age-specific interventions [24].

Signs and symptoms observed were typical of campylobacteriosis, with most admissions having diarrhoea and abdominal pain recorded [4]. Reports suggest older campylobacteriosis cases may report some signs and symptoms, including bloody diarrhoea, abdominal pain, vomiting and fevers less frequently [25]. Our data support this juxtaposition, although it seems unlikely that agerelated differences in presentation would impact a Campylobacter diagnosis due to the proclivity of stool testing.

Reported LOS vary dependent upon the measures of central tendency used. We reported mean and median LOS of 3.5 and 2.0 days, while for acute non-same day admissions the mean and median LOS were 4.9 and 4.0 days. These appear comparable to findings elsewhere $[19,26]$. Similarly we observed cases with bacteraemia or underlying comorbidities to have longer LOS [27, 28]. Notably $40 \%$ of admissions involved same day care, illustrating the spectrum of hospitalisation, while linkage of surveillance and laboratory data revealed $10 \%$ of non-hospitalised cases presented to EDs for non-admitted acute care. Reasons for this ED burden might include perceived symptom severity and lack of access to a GP [29].

One third of patients had a comorbidity, a proportion similar to studies describing hospitalisations for infectious gastroenteritis [27]. These patients were generally older, took longer to present and had longer LOS. Diabetes was the most frequently recorded comorbidity, followed by malignancies and chronic kidney disease. While some evidence suggest diabetes and chronic kidney disease increase risk for Campylobacter enterocolitis [30, 31], relationships between Campylobacter infection and malignancies are more well established [32, 33]. Admissions with comorbidities experienced electrolyte imbalances, renal impairment, hypotension, acute confusion and acute readmission more frequently.

Half of acute admissions had blood cultures, with a positivity rate of $7.5 \%$. These admissions involved older patients with higher comorbidity levels, although associated mortality was low, features consistent with findings elsewhere $[28,34]$. Although no deaths occurred among blood culture positive cases, there was one death in a case diagnosed with blood culture negative sepsis.

Our study suggests renal impairment may occur more frequently in patients' hospitalised with campylobacteriosis.
This is supported by studies describing increased renal dysfunction among hospitalised gastroenteritis cases [30, 35, 36]. Furthermore comorbidities including kidney disease, hypertension, diabetes and a history of organ transplantation have been shown to increase AKI risk among patients with infectious diarrhoea [30].

Around $7 \%$ of admissions underwent surgical or invasive diagnostic procedures, with appendectomies and colonoscopies most frequently performed. Among appendix specimens, 50\% showed histological evidence of inflammation, although specimens were not microbiologically tested. The issue of Campylobacter-associated appendicitis remains contentious, with a study reexamining archived appendices using nucleic acid testing detecting C. jejuni in $22 \%$ of specimens [37].

Limitations with our study include the cross-sectional design and generalisability of findings given the small provincial source population [38]. Local epidemiology is also an important consideration, with ACT campylobacteriosis rates higher than most other Australian states [3]. Differences in health care utilisation also require consideration [39]. We assumed hospitalisation would most likely occur in the public sector, with the extent of private hospital admissions being uncertain. Given the size and role of private hospitals in Australia's health care system [40], our calculated rate of hospitalisation for ACT residents may be an underestimation. We were unable to estimate predictors of hospitalisation, however access to integrated Australian hospital and primary care data is lacking [41], making comparisons challenging. While plausible, our findings regarding AKI and renal impairment require further assessment. AKI diagnoses were not validated against a standard, e.g. Kidney Disease: Improving Global Outcomes (KDIGO) criteria [42], while our assessment of renal impairment via serum creatinine levels was simplified.

\section{Conclusion}

Hospitalisation data provides an important indicator of the burden and severity of campylobacteriosis. Improving the accuracy and completeness of Campylobacter-associated hospitalisation data, in conjunction with detailed clinico-epidemiological characterisation is of tangible benefit to clinicians and public health decision makers. Undertaking observational studies, including genomic assessment of virulence factors, would improve understanding of patient and pathogen specific predictors of hospitalisation.

\section{Abbreviations}

ACT: Australian Capital Territory; AKI: Acute Kidney Injury; CCl: Charlson Comorbidity Index; ED: Emergency Department; GP: General Practitioner; ICD: International Classification of Diseases; LOS: Length of Stay; NSW: New South Wales; UR: Unit Record; US: United States 


\section{Acknowledgments}

We would like to thank the following: ACT Pathology for provision of data on public hospital-generated Campylobacter isolates; ACT Health Protection Service for provision of surveillance data for campylobacteriosis in the ACT: hospital data services staff provision of administrative data for Campylobacter-associated admissions and medical records staff for facilitating access to case medical records identified via morbidity coding and/or data linkage.

\section{Authors' contributions}

CM planned the study, undertook data collection, performed analysis and drafted the manuscript. CM, KK, LS and MK all contributed to and approved the final manuscript.

\section{Funding}

The National Health and Medical Research Council provided funding to authors CM [APP107490] and MK [APP1145997]. The funding body had no role in the design of the study, collection, analysis and interpretation of data, or in writing of the manuscript.

\section{Availability of data and materials}

The data that support the findings of this study are available from the ACT Government Health Directorate and Calvary Health Care (Bruce). Restrictions apply to the availability of these data, which were used under approvals for the current study and so are not publicly available. Data are however available from the authors upon reasonable request and with permission of the ACT Government Health Directorate and Calvary Health Care (Bruce).

\section{Ethics approval and consent to participate}

Ethics approvals were obtained from the Human Research Ethics Committee of the ACT Government Health Directorate (Ref. ETHLR.14.121) Calvary Health Care (Bruce) (Ref. 22-2014) and the Australian National University (Ref. 2014/ 223). These approvals included permission to access inpatient medical records subject to the study dataset being anonymised before use. Individual consent to participate was not required.

\section{Consent for publication}

Not applicable.

\section{Competing interests}

The authors declare they have no competing interests.

\section{Author details}

'National Centre for Epidemiology and Population Health, Research School of Population Health, Australian National University, Canberra, ACT 2602, Australia. ${ }^{2}$ Department of Microbiology, Canberra Hospital and Health Services, Canberra, ACT, Australia. ${ }^{3}$ School of Public Health, University of Queensland, Brisbane, QLD, Australia.

Received: 3 June 2020 Accepted: 8 December 2020

Published online: 06 January 2021

\section{References}

1. European Food Safety Authority and European Centre for Disease Prevention and Control (EFSA and ECDC). The European Union summary report on trends and sources of zoonoses, zoonotic agents and food-borne outbreaks in 2017. EFSa J. 2018;16(12):e05500.

2. Geissler AL, Bustos Carrillo F, Swanson K, et al. Increasing campylobacter infections, outbreaks, and antimicrobial resistance in the United States, 2004-2012. Clin Infect Dis. 2017:65(10):1624-31.

3. Moffatt CR, Glass K, Stafford R, D'Este C, Kirk MD. The campylobacteriosis conundrum - examining the incidence of infection with Campylobacter sp. in Australia, 1998-2013. Epidemiol Infect. 2017;145(4):839-47.

4. Blaser MJ, Engberg J. Clinical aspects of campylobacter jejuni and campylobacter coli infections. Campylobacter, Third Edition: American Society of Microbiology; 2008. p. 99-121.

5. Louwen R, van Baarlen P, van Vliet AH, van Belkum A, Hays JP, Endtz HP. Campylobacter bacteremia: a rare and under-reported event? Eur J Microbiol Immunol (Bp). 2012;2(1):76-87.

6. Pope JE, Krizova A, Garg AX, Thiessen-Philbrook H, Ouimet JM. Campylobacter reactive arthritis: a systematic review. Semin Arthritis Rheum. 2007;37(1):48-55.
7. Poropatich $\mathrm{KO}$, Walker $\mathrm{CL}$, Black RE. Quantifying the association between campylobacter infection and Guillain-Barre syndrome: a systematic review. J Health Popul Nutr. 2010;28(6):545-52.

8. Thomas MK, Murray R, Flockhart $L$, et al. Estimates of foodborne illnessrelated hospitalizations and deaths in Canada for 30 specified pathogens and unspecified agents. Foodborne Pathog Dis. 2015;12(10):820-7.

9. Kirk M, Ford L, Glass K, Hall G. Foodborne illness, Australia, circa 2000 and circa 2010. Emerg Infect Dis. 2014;20(11):1857-64.

10. Scallan E, Hoekstra RM, Angulo FJ, et al. Foodborne illness acquired in the United States--major pathogens. Emerg Infect Dis. 2011;17(1):7-15.

11. Australian Bureau of Statistics (ABS). Australian Demographic Statistics, June Quarter 2017. Accessed 12 Sept.

12. Charlson ME, Pompei P, Ales KL, MacKenzie CR. A new method of classifying prognostic comorbidity in longitudinal studies: development and validation. J Chronic Dis. 1987:40(5):373-83.

13. Ellis M. Preventing microbial translocation in haematological malignancy. $\mathrm{Br}$ J Haematol. 2004:125(3):282-93.

14. Helms M, Simonsen J, Molbak K. Foodborne bacterial infection and hospitalization: a registry-based study. Clin Infect Dis. 2006:42(4):498-506.

15. Scallan E, Griffin PM, McLean HQ, Mahon BE. Hospitalisations due to bacterial gastroenteritis: a comparison of surveillance and hospital discharge data. Epidemiol Infect. 2018;146(8):954-60.

16. Harvala H, Rosendal T, Lahti E, et al. Epidemiology of Campylobacter jejuni infections in Sweden, November 2011-October 2012: is the severity of infection associated with C. jejuni sequence type? Infect Ecol Epidemiol. 2016;6:31079.

17. The Institute of Environmental Science and Research Ltd. Notifiable Diseases In New Zealand: Annual Report 2017. Porirua, New Zealand, 2019.

18. Schielke A, Rosner BM, Stark K. Epidemiology of campylobacteriosis in Germany - insights from 10 years of surveillance. BMC Infect Dis. 2014;14:30

19. Ruzante JM, Majowicz SE, Fazil A, Davidson VJ. Hospitalization and deaths for select enteric illnesses and associated sequelae in Canada, 2001-2004. Epidemiol Infect. 2011:139(6):937-45.

20. Olson CK, Ethelberg S, van Pelt W, Tauxe RV. Epidemiology of campylobacter jejuni infections in industrialized nations. Campylobacter, Third Edition: American Society of Microbiology; 2008. p. 163-89.

21. Chen Y, Liu BC, Glass K, Kirk MD. High incidence of hospitalisation due to infectious gastroenteritis in older people associated with poor self-rated health. BMJ Open. 2015:5(12):e010161.

22. Christensen KL, Holman RC, Steiner CA, Sejvar JJ, Stoll BJ, Schonberger LB. Infectious disease hospitalizations in the United States. Clin Infect Dis. 2009: 49(7):1025-35.

23. Nichols GL, Richardson JF, Sheppard SK, Lane C, Sarran C. Campylobacter epidemiology: a descriptive study reviewing 1 million cases in England and Wales between 1989 and 2011. BMJ Open 2012; 2(4).

24. Barker SF, Zomer E, O'Toole J, et al. Cost of gastroenteritis in Australia: a healthcare perspective. PLoS One. 2018;13(4):e0195759.

25. White AE, Ciampa N, Chen Y, et al. Characteristics of campylobacter and Salmonella infections and acute gastroenteritis in older adults in Australia, Canada, and the United States. Clin Infect Dis. 2019;69(9):1545-52.

26. Samuel MC, Vugia DJ, Shallow S, et al. Epidemiology of sporadic campylobacter infection in the United States and declining trend in incidence, FoodNet 1996-1999. Clin Infect Dis. 2004;38(Suppl 3):S165-74.

27. Jansen A, Stark K, Kunkel J, et al. Aetiology of community-acquired, acute gastroenteritis in hospitalised adults: a prospective cohort study. BMC Infect Dis. 2008:8:143.

28. Nielsen H, Hansen K, Gradel K, et al. Bacteraemia as a result of campylobacter species: a population-based study of epidemiology and clinical risk factors. Clin Microbiol Infect. 2010;16(1):57-61.

29. Kraaijvanger N, Rijpsma D, van Leeuwen $H$, Edwards M. Self-referrals in the emergency department: reasons why patients attend the emergency department without consulting a general practitioner first-a questionnaire study. Int J Emerg Med. 2015;8(1):46.

30. Bradshaw C, Zheng Y, Silver SA, Chertow GM, Long J, Anand S. Acute kidney injury due to diarrheal illness requiring hospitalization: data from the National Inpatient Sample. J Gen Intern Med. 2018;33(9):1520-7.

31. Neal KR, Slack RC. Diabetes mellitus, anti-secretory drugs and other risk factors for campylobacter gastro-enteritis in adults: a case-control study. Epidemiol Infect. 1997;119(3):307-11.

32. Gradel KO, Schonheyder HC, Dethlefsen C, Kristensen B, Ejlertsen T, Nielsen H. Morbidity and mortality of elderly patients with zoonotic Salmonella and campylobacter: a population-based study. J Inf Secur. 2008;57(3):214-22. 
33. Pacanowski J, Lalande V, Lacombe K, et al. Campylobacter bacteremia: clinical features and factors associated with fatal outcome. Clin Infect Dis. 2008;47(6):790-6.

34. Hussein K, Raz-Pasteur A, Shachor-Meyouhas Y, et al. Campylobacter bacteraemia: 16 years of experience in a single Centre. Infect Dis (Lond). 2016:48(11-12):796-9.

35. Ena J, Afonso-Carrillo RG, Bou-Collado M, et al. Epidemiology of severe acute diarrhea in patients requiring hospital admission. J Emerg Med. 2019; 57(3):290-8.

36. Janssen van Doorn $\mathrm{K}$, Pierard $\mathrm{D}$, Spapen $\mathrm{H}$. Acute renal dysfunction in Salmonella gastroenteritis. J Clin Gastroenterol. 2006;40(10):910-2.

37. Campbell LK, Havens JM, Scott MA, Lamps LWJMP. Molecular detection of Campylobacter jejuni in archival cases of acute appendicitis 2006; 19(8): 1042-1046.

38. Australian Bureau of Statistics (ABS). 2016 Census QuickStats - Australian Capital Territory. Available at: https://quickstats.censusdata.abs.gov.au/ census_services/getproduct/census/2016/quickstat/8ACTE?opendocument. Accessed 18 Mar 2020

39. Ailes E, Scallan E, Berkelman RL, Kleinbaum DG, Tauxe RV, Moe CL. Do differences in risk factors, medical care seeking, or medical practices explain the geographic variation in campylobacteriosis in foodborne diseases active surveillance network (FoodNet) sites? Clin Infect Dis. 2012;54(Suppl 5):S464-71,

40. Australian Institute of Health and Welfare (AlHW). Australia's health 2014. Canberra: AlHW. p. 2014

41. Canaway R, Boyle DI, Manski-Nankervis JE, et al. Gathering data for decisions: best practice use of primary care electronic records for research. Med J Aust. 2019;210(Suppl 6):S12-S6.

42. Kellum JA, Lameire N, Aspelin P, et al. Kidney disease: improving global outcomes (KDIGO) acute kidney injury work group. KDIGO Clin Practice Guideline Acute Kidney Injury. 2012;2(1):1-138,

\section{Publisher's Note}

Springer Nature remains neutral with regard to jurisdictional claims in published maps and institutional affiliations.

Ready to submit your research? Choose BMC and benefit from:

- fast, convenient online submission

- thorough peer review by experienced researchers in your field

- rapid publication on acceptance

- support for research data, including large and complex data types

- gold Open Access which fosters wider collaboration and increased citations

- maximum visibility for your research: over $100 \mathrm{M}$ website views per year

At $\mathrm{BMC}$, research is always in progress.

Learn more biomedcentral.com/submissions 